\title{
A EDUCAÇÃO AMBIENTAL E OS INSETOS: APRENDIZADO INTERATIVO NAS ESCOLAS PÚBLICAS DE CAMPOS DOS GOYTACAZES, RJ.
}

\author{
Thais Berçot Pontes Teodoro' \\ Gabriela Carvalho de Souza Santos ${ }^{2}$ \\ Guillermo Gonçalves Alpande ${ }^{3}$ \\ Magali Hoffmann ${ }^{4}$
}

\begin{abstract}
Resumo: A inclusão de valores ambientais pode despertar nos indivíduos um potencial transformador, permitindo que este contribua para um mundo mais ético e sustentável. De forma a suprir parte da lacuna na educação básica, este projeto objetivou a difusão da entomologia para os alunos da rede pública de ensino de Campos dos Goytacazes - RJ. Através de atividades como exposição de coleção entomológica, palestras interativas, mostra de vídeos e aplicação de questionários, são transmitidos os conceitos, importâncias e curiosidades dos principais grupos de inseto. Os alunos puderam ver e sentir a textura dos exemplares de perto. Isso entusiasma e instiga a curiosidade das crianças, o que torna o aprendizado mais divertido e ajuda na fixação. Os questionários iniciais e finais avaliaram a mudança de pensamento sobre os assuntos abordados. Os resultados demonstram progresso no conhecimento de alguns aspectos importantes dos insetos.
\end{abstract}

Palavras-chave: Ensino; Entomologia; Sustentabilidade; Extensão universitária.

\footnotetext{
${ }^{1}$ Ciências Biológicas / Universidade Estadual Norte Fluminense, Brasil. E-mail: thaisbercot@yahoo.com.br.

${ }^{2}$ Agronomia / Universidade Estadual Norte Fluminense, Brasil. E-mail: gabrielauenf@yahoo.com.br.

${ }^{3}$ Agronomia / Universidade Estadual Norte Fluminense, Brasil. E-mail: guillermo.alpande@gmail.com.

${ }^{4}$ Ciências Biológicas / Universidade Estadual Norte Fluminense, Brasil. E-mail: magali@uenf.br.
} 